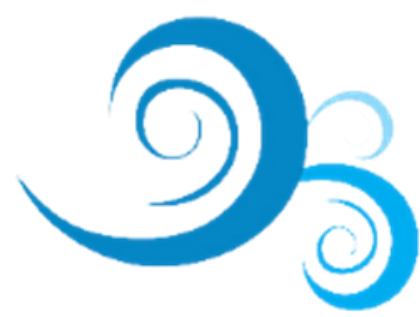

\title{
AMAZONIA Y EL REPLANTEO DE LA INTEGRACIÓN ELÉCTRICA REGIONAL: ESTRATEGIAS REGIONALES DE LOS CAPITALES POSICIONADOS EN AMÉRICA DEL SUR
}

\author{
LUIS FERNANDO NOVOA GARZON \\ Professor Adjunto do Departamento de Ciências Sociais da Universidade \\ Federal de Rondônia (UNIR), Porto Velho (RO), Brasil. \\ ORCID: http://orcid.org/0000-0003-2280-7959 \\ I.novoa@unir.br
}

\begin{abstract}
Resumen: En este artículo revisamos la trayectoria de los programas de integración de infraestructura en el continente sudamericano, identificando modulaciones en los ciclos de gobiernos alternadamente liberales y progresistas. A pesar del acento retórico en la consigna de la "soberanía energética" sobresalió en los últimos años el pragmatismo de las asociaciones entre capitales extranjeros que redundaran en una franca multilateralización de los regionalismos inicialmente dibujados. La región amazónica fue víctima primera de tal descomposición tornándose un abanico de enclaves instalados y por instalar. Grandes empresas ubicadas en la región crecen como proveedoras mundiales de materia prima a gran escala y para eso cuentan con la flexibilidad creciente de los marcos regulatorios de los sectores de energía, minería y de infraestructura. La capacidad diferencial de los sectores que representan los intereses de los sectores de commodities contrasta con la capacidad de las poblaciones locales para incidir en la pretensión mínima de hacer cumplir marcos de protección elementales. La prospección de las estrategias regionales de los capitales es lo que tratamos de investigar en este ensayo retrospectivo-prospectivo, en el marco de recientes tratativas de integración eléctrica regional, con basis en viejos e nuevos proyectos de generación y trasmisión eléctrica, en la región amazónica.
\end{abstract}

Palabras-clave: Infraestructuras regionales; Grandes Proyectos de Inversión. Especialización territorial de la Amazonia. Integración eléctrica regional.

\section{AMAZONIA AND REISSUING REGIONAL ELECTRICITY INTEGRATION: REGIONAL STRATEGIES OF THE CAPITALS SITUATED IN SOUTH AMERICA}

\begin{abstract}
In this article we review the trajectory of infrastructure integration programs in the South American, identifying modulations in the cycles liberal-conservative and progressive governments. Despite the rhetorical accent on the slogan of "energy sovereignty", the pragmatism of the associations between foreign capitals has stood out in recent years, resulting in a frank multilateralization of the initially drawn regionalisms. The Amazon region was the first victim of such decomposition, becoming a range of exploitation systems installed and to be installed. Large companies located in the region grow as global suppliers of raw materials on a large scale because they have the increasing flexibility of regulatory frameworks in the energy, mining and infrastructure sectors. The huge capacity of the sectors that represent the interests of the commodity sectors contrasts with the capacity of local populations to influence the minimal claim to enforce elementary protection frameworks. The investigation of new regional strategies of capitals is what we study here in this retrospective-prospective essay, based on recent regional electricity integration discussions, specifically new projects of electricity generation and transmission, in the Amazon region.
\end{abstract}

Key words: Regional infrastructure; Regional electrical integration. Large Investment Projects. Territorial specialization of the Amazon. 


\section{AMAZÔNIA E A RETOMADA DA INTEGRAÇÃO ELÉTRICA REGIONAL: ESTRATÉGIAS REGIONAIS DOS CAPITAIS POSICIONADOS NA AMÉRICA DO SUL}

RESUMO: Neste artigo revisamos a trajetória dos programas de integração de infraestrutura no continente sul-americano, identificando modulações nos ciclos de governos alternadamente liberais y progressistas. Apesar da ênfase retórica embutida na bandeira da "soberania energética" o que se observou nos últimos anos foi o pragmatismo das associações entre capitais estrangeiros que redundaram em uma franca multilateralização dos regionalismos inicialmente esboçados. A região amazônica foi vítima primeira do desmonte dos projetos integracionistas, tornando-se tornando- se um cardápio de enclaves instalados e por instalar. Grandes empresas localizadas na região consolidamse como como provedoras mundiais de matérias-primas em larga escala e para isso contam com a flexibilização crescente dos marcos regulatórios dos setores de energia, mineração e infraestrutura. A capacidade diferencial dos setores que representam os interesses dos setores de commodities contrasta com a capacidade das populações locais para incidirem em torno da pretensão mínima de que se cumpram marcos de proteção elementares. A prospecção das estratégias regionais dos capitais é o que procuramos fazer neste ensaio retrospectivo-prospectivo, nos marcos de tratativas recentes de integração elétrica regional, com base em velhos e novos projetos de geração e transmissão elétrica, na região amazônica.

PALAVRAS-CHAVE: Infraestruturas regionais; Grandes Projetos de Investimento. Especialização territorial da Amazônia. Integração elétrica regional.

\section{Introducción}

La crisis global instaurada en 2008 señala un nuevo giro en el torniquete de saqueos y expropiaciones, que generó en los años siguientes reiterados ataques contra los bienes públicos, sociales y ambientales en Latinoamérica. En el caso brasileño, el último período del ciclo de gobiernos progresistas sirvió para consolidar el núcleo de los negocios especializados en el procesamiento de los recursos naturales, a partir de grandes grupos multinacionales. La vinculación más estrecha del país a las cadenas globales de valor fue una construcción práctico-discursiva en que los capitales "nacionales" delineaban la defensa de la ampliación de sus posiciones en el mercado externo a cambio de una mayor apertura y estímulos a las inversiones extranjeras directas. Se puede observar en la dinámica de expansión de las grandes empresas brasileñas, una internacionalización de doble sentido, como demuestran las cambiantes estructuras financieras de grupos como Embraer, JBS, Petrobras y Vale (SANTOS, 2015). Tal característica se puede verificar sea en las ramificaciones arriba sea en las ramificaciones abajo de sus actividades-núcleo (backward and forward linkages), con variables y irregulares tensiones en la gestión y control de esas corporaciones, a depender del gobierno de turno y de sus metas más o menos aglutinadoras de las cadenas productivas existentes, incompletas y dependientes. 
Este tensionamiento fue igualmente determinante en la trayectoria de los sectores de infraestructura considerados estratégicos, en ese periodo (WERNER, 2019). Sectores de agua, energía, transportes y comunicaciones tienen el poder de definir la dirección y el ritmo de la acumulación de capitales, dado que todos los demás sectores económicos dependen de tales suministros, en cantidad y calidad adecuadas. El acceso privado a estos sectores y su patrón de organización conforman el perfil productivo del país y el protagonismo de determinados actores y grupos económicos. A partir de la década de 1990, la privatización de estos sectores, o de otra manera, el incremento de la "participación del sector privado" en ellos, fue anunciada como una condición para nuevas inversiones y para acceder a nuevos créditos internacionales vinculados al pago de la deuda pública. La privatización de la infraestructura, al delimitar el lugar concebible del "Estado regulador", colocaba, de antemano, al capital extranjero en una posición destacada en el nuevo bloque de poder que se instaló en Brasil desde entonces (CANO, 2017).

Tratamos de exponer en ese artículo como se entalló la reversión del papel catalizador que tuvo Brasil en el proceso de integración energética regional, a partir de un continuum que pasa por la privatización de su estructura de generación eléctrica, por la deshidratación de sus órganos reguladores y coordinadores y también por la abrumadora presencia de las capitales estadounidense y chinos en la región. En el vacío de esfuerzos integracionistas de los estados nacionales sudamericanos, las burguesías internas - que sobrevivieron a estos procesos de liberalización, se vincularon de forma aún más automática a los mercados internacionales como proveedores, intermediarios o distribuidores de redes globales oligopólicas.

Las iniciativas puntuales de interconexión eléctrica que están el horizonte de los inversionistas remarcan ventajas comparativas estáticas de los países de la región, es decir, buscan optimizar procesos de extracción y exportación de productos con uso intensivo de recursos naturales. Lógica que ya estaba presente en los proyectos originalmente diseñados en el ámbito de la Iniciativa de Integración de la Infraestructura Regional Sudamericana (tal como fue concebida por em BID en 2000), pero también durante el interludio IIRSA-COSIPLAN (2008-2016), a pesar de los apuntes retóricos en sentido contrario. Lo que demostraremos a continuación es que la misma lógica fragmentaria de la planificación territorial, característica de los 
conglomerados empresariales, sigue siendo la planificación realmente existente en escala regional o subregional (FUSER; ABRÃO, 2020).

Las instituciones financieras internacionales (IFIS), especialmente el FMI, el Banco Mundial (BIRD) y el Banco Interamericano de Desarrollo (BID) -que antes hacían de la deuda pública un instrumento para profundizar las privatizaciones y las desregulaciones resultantes- buscaron, durante ese período, articularse con ese campo de fuerzas "interno" para mantener de pie agendas de liberalización similares. Si antes (en los años 1990) no era posible hablar consistentemente de un "nuevo regionalismo" debido a los procesos de desmantelamiento de los mercados nacionales y regionales y por la fragmentación espacial en función a la demanda externa, el ciclo (entre 2000 y 2016) de los llamados gobiernos progresistas, por varios países de América Latina, proporcionó ajustes periféricos imprevistos a los flujos de capitales de las economías centrales, o sea, hubo más continuidades que rupturas (DOS SANTOS, 2019). La realización de infraestructuras regionales como grandes desagües físicos de materias primas exportables para el mercado externo, en una primera fase, dependía de acuerdos previos, en la escala de los países (dentro de sus bloques hegemónicos). En la fase actual, ya cristalizados los intereses rentistas y neoextractivistas, megaproyectos y zonas económicas especiales tienden a prevalecer por medio de acuerdos sectoriales privados, en el marco de fusiones, adquisiciones y gobernanzas oligopólicas.

Desregulaciones ambientales y flexibilizaciones de derechos territoriales señalan el intento de superar barreras, físicas y simbólicas, que detengan o condicionen nuevas inversiones en la Amazonia. La búsqueda de dinamismos adicionales y extraordinarios para la realización de valor es lo que preside la lógica de los megaproyectos concernidos en las propuestas de integración eléctrica regional en circulación.

Nuestra hipótesis, con basis en la trayectoria político institucional de los procesos integracionistas sudamericanos en las últimas dos décadas, apunta para una naturalización de la planificación territorial volcada hacia al procesamiento y exportación de materias-primas en larga escala. Descomponiendo la lógica de los Grandes Proyectos de Inversión, que están en el ámago de esa misma planificación tratamos de demonstrar cómo se desdoblan las dinámicas de desterritorialización y reterritorialización resultantes de la interpenetración de los procesos decisorios 
empresariales y gubernamentales, movidos por estrategias transescalares (BRENNER, 2004).

Al final, se presentan ejemplos concretos de los efectos de la renuncia, que se prenuncia con el anuncio de la privatización de ELETROBRAS, a una política de integración energética que proporcionaría a la región soberanía energética y la posibilidad de implementar políticas económicas y industriales activas y sostenibles. Una política de integración regional basada en el usufructo común de las externalidades positivas de las inversiones extranjeras, ni siquiera merecería tal nominación pues trasformaría nuestros territorios en péndulos, colgados en rumbos predecibles, objetos de cálculo y desecho.

\section{La IIRSA que perdura: marco lógico de nuevas funcionalizaciones territoriales en Sudamérica}

La reanudación de los proyectos de Iniciativa de Integración de Infraestructura Regional de Sudamericana (IIRSA), o programas correlatos, y la defensa abierta de un mayor alineamiento hemisférico, es decir, la alineación a la precedencia plena del capital norteamericano por parte de los grupos económicos más influyentes en los países de América del Sur, dejaba claro - especialmente después de 2016, en Brasil - que el precio de la crisis sería pagado proporcionalmente por los segmentos sociales más vinculados a territórios aún no incorporados y monopolizados. La expulsión y el exterminio de las comunidades tradicionales, de campesinos y pueblos originarios en la Amazonia se impuso como tarea precipua para las burguesías de encomienda, en la medida en la simples existencia de tales grupos es una prueba de viabilidad de usos racionales, comunes, múltiples y compartidos de los territorios y sus recursos. Por eso no se trata de una desposesión física apenas más de una destitución de alternativas no mercantiles del horizonte histórico de la región, (SVAMPA, 2019)

En este escenario, la planificación concebible es la corporativa-empresarial, en regímenes de asociaciones y concesiones, que representan un atajo, una preeminencia para el acceso a nuevos bloques de riqueza. Frente a la "representación directa" de las grandes empresas mineras, agrícolas y ganaderas y de infraestructura, las instituciones nacionales patentan su subrepresentación, a veces acentuando la retórica patriótica, a veces dando lugar a la intimidación o a la truculencia contra las voces no alineadas. 
Conviene recordar que el "espíritu" (que ahora resurge) de la Iniciativa de Integración de Infraestructura Regional de Sudamericana (IIRSA) era multiplicar áreas económicamente y jurídicamente seguras para las inversiones extranjeras, especialmente dirigidas a los flujos de materias primas y productos básicos estratégicos para las cadenas de producción mundializadas. En verdad, la reorientación "hacia dentro", en los marcos nacionales, de cada país miembro de la Iniciativa, remarcada en la Cumbre de los Pueblos de 2006 en Cochabamba, y su absorción por la Unión de Naciones Sudamericanas (UNASUR) en 2008, no alteró ese guion. (VILLEGAS, 2011; MARTINEZ, 2013)

Cuando IIRSA renació en 2008 como "agenda de integración física" de los países sudamericanos (UNASUR) - a cargo de su Consejo Sudamericano de Infraestructura y Planificación (COSIPLAN) -se universalizó como se fuera una herramienta técnica y neutral de planificación regional. A pesar de las metas de endogeneizacion del crecimiento, de la sostenibilidad ambiental y de la inclusión social artificialmente acoplados, no hubo alteración de los niveles de concentración e internacionalización de los capitales en la región (DOS SANTOS, 2016). Los calificativos "endógeno", "ambiental" y "regional", en realidad, componían un pacto interclasista que presuponía el silenciamiento preventivo de la crítica y la segregación de los conflictos sociales y ambientales.

Desde entonces hasta hoy, la "integración física" pasó a ser una meta considerada aceptable y necesaria por distintas matices políticas y colegiados empresariales, constituyendo un consenso político-empresarial transideológico. El término deliberadamente neutral o aséptico supone una naturalización de un nivel técnico deseable de conectividad económica, como si la movilidad de los capitales pudiera ser gobernada de manera homogénea y multidireccional. En verdad, los "ejes de integración" propuestos para la planificación territorial regional son ejes preferenciales de concentración de capitales que dan acceso a habilidades y rentabilidades de gran alcance, esa es la actualidad del método o de la lógica inscripta en la IIRSA que perdura en las negociaciones bilaterales o trilaterales en curso.

|La descomposición de UNASUR entre 2018 y 2019 y la creciente apuesta en amplios acuerdos de protección de inversiones y de estímulo a exportación de commodities, no retiró de escena los proyectos de "integración física" sino que transfirió la arena de decisión o regulación sobre los mismos para el universo 
corporativo transnacional y sus Instituciones Financieras. Con el malogro de los intentos de crear una "clave posliberal y poshegemónica" que remodelase las políticas económicas y de comercio exterior dos los países sudamericanos, a partir de la debacle de las frentes o partidos progresistas - particularmente en Brasil, Argentina, Ecuador y Chile -se acentúa el pragmatismo tanto en las tratativas de comercio cuanto en los procesos de interconexión de infraestructura. (VITELLI; MILANI, 2019)

En el pasaje anterior IIRSA-COSIPLAN, el capital, globalizado y concentrado en la región, ganó institucionalidad adicional, que le ofreció espacios propios para la construcción de arreglos sectoriales y territoriales. Retirada la moldura institucional, prosiguen las iniciativas privadas de integración energética y de modales de transporte con apoyo sea de las Instituciones Financieras Interamericanas (Banco Interamericano de Desarrollo, Corporación Andina de Fomento y FONPLATA) sea de las Instituciones vinculadas a capitales chinos (Banco de Desarrollo Chino, Banco Asiático de Inversión en Infraestructura y el Banco de los BRICS). Mismo en un escenario de profundización de la crisis, son ofrecidos escenarios viabilizan protoburguesías o gerencias cosmopolitas a gestionar la próxima ola de expansionismo de las grandes corporaciones en la región. (MINEIRO et al, 2018; GARCIA, 2020)

Persiste una masa ociosa de capital sobreacumulado (en China y el sudeste asiático y también en los Estados Unidos y en algunos países europeos), ansiosa por señales adicionales de buena voluntad hacia los inversores, ansiosa por medidas que ofrezcan nuevos espacios para la valorización financiera y operacional (con basis en inversiones directas). El mantenimiento del flujo de inversiones, dependiendo de su canalización a sectores con un alto rendimiento garantizado, duela a quien le duela, con el sacrificio de los últimos fragmentos de democracia existente en el continente sudamericano, regulariza las pierdas internacionales, es decir, las sangrías comerciales y financieras; lo que favorece a los actores que se alinearon con los capitales hegemónicos en las recomposiciones de los bloques de poder nacionales y subregionales, ocurridas en los últimos años.

En el caso brasileño, se pusieron en acción esfuerzos combinados para hacer operativa una estatalidad paralela de un Estado privatizado a servicio de los grupos económicos basados en los recursos naturales. Por lo tanto, el bloque en el poder en Brasil viene exigiendo una apertura externa aún más incondicional, especialmente con la Alianza Transpacífico (TPP) y el PROSUL, em su última versión, una zona de libre 
comercio tricontinental que busca imponer un régimen de soberanía absoluta de las inversiones privadas (NEVES, 2020).

\section{Una mirada sobre los megaproyectos y la planificación energética y territorial derivada}

La producción y disponibilidad de energía no son aleatorias. La energía es básicamente una fuerza productiva-destructiva, por lo tanto, una fuerza direccionadora de la acumulación capitalista. El modelo energético vigente reproduce de forma intensificada la naturaleza concentradora del modelo económico que impulsa. El modelo extractivista que atravesó gobiernos de distintos matices en Brasil, fue construido hábilmente por lobbies sectoriales compuestos por una pléyade de asociaciones de concesionarios, distribuidoras, grandes consumidores, además de parlamentarios, directores de empresas estatales y ministros de ocasión.

Dreiffus (1981, p. 162), al analizar la génesis social y política del Estado autoritario en Brasil (1964-1985), alega que una élite orgánica del bloque económico multinacional y asociado "modelaría las fuerzas sociales burguesas en una clase, un proceso que culminaría con el involucramiento de los intereses multinacionales y asociados del poder privado al gobierno público de Brasil". De modo similar, las fracciones del actual bloque dominante en Brasil se estructuran para constituir una parcela del Estado en una proporción variable de asociación y subordinación entre capitales internos y extranjeros, autodenominándose después como catalizadores de los intereses nacionales. ${ }^{1}$

Los Grandes Proyectos de Inversión (GPI) son resultado explícito de la confluencia de estrategias desencadenadas a partir de distintas escalas y niveles de poder e proporcionan saltos o huidas para adelante del capitalismo brasileiro. Está en su génesis última. Fue durante la dictadura cívico-militar que se agregó un horizonte geopolítico al llamado modelo oligárquico de apropiación territorial, vigente en los años 1950 y 1960, y que, por ejemplo, presidió la construcción de Brasilia "en una gigantesca cruzada por carretera, sin disciplinar la ocupación, la posesión y la formación de propiedades rurales en los frentes de expansión de la sociedad nacional" (MOREIRA, 2003, p. 185).

\footnotetext{
${ }^{1}$ En el slogan del Gobierno Bolsonaro se subraya: "Brasil arriba de todo!".
} 
Los GPI, desde entonces, se convirtieron en instrumento-estándar de intervención territorial y de actualización de la división interregional del trabajo en beneficio del bloque de poder hegemónico en el país. A pesar de las variaciones de sus efectos de acuerdo con la actividad desarrollada por el Gran Proyecto y en cuanto al grado de consolidación de la región en la que se encuentra, existieron características comunes en los GPI. Rosélia Piquet (2007, p. 17-21) presenta una síntesis suficientemente abarcadora de sus efectos comunes: distorsión de la pirámide etaria, desestructuración familiar y de lazos de vecindad, aumento de la violencia, de la prostitución, del comercio y uso de drogas, del cambio de perfil ocupacional de forma temporal y sin planificación para la recomposición o mantenimiento de actividades económicas anteriores o la creación de nuevas actividades perennes después de las obras, rediseño del territorio con la conversión del área/ciudad en apoyo pasivo de la logística del emprendimiento y cambios en la representación política de los intereses, en términos de una sobreposición asimétrica de escalas.

A fines de la década de 1980 y principios de los años 1990, ya era posible dimensionar, de una manera más amplia, el significado de los GPI. Ribeiro (1988) consideraba que los grandes proyectos ofrecían una unidad de análisis muy apropiada para la exploración etnográfica de las intersecciones espaciales, de las dinámicas demográficas y específicamente de la mano de obra requerida y de los desequilibrios de poder instaurados. Un gran proyecto, por su escala de interpenetraciones, es siempre el inicio y el final de un ensamblaje territorial dado y se configura como traducción espacial de una compleja acumulación de fuerzas sociales en disputa; siendo los sectores con más capacidad interescalar nivel los que detienen el centro de gravedad política del proyecto.

Tal interescalaridad sería entonces una forma piramidal de tesitura y de articulación de los grupos de poder en el marco de los GPIs. Dependiendo de la articulación empresarial hecha, queda bajo su ordenamiento la política ambiental, la de la tenencia de la tierra y, de paso, la política indígena. Suspendidos los propósitos descolonizadores y preservados los privilegios de origen permanente, los defensores de GPI declaran suspendidos los territorios indígenas. João Pacheco (1990, p. 31), por ejemplo, ya identificaba una fuerza normativa intrínseca a los grandes proyectos, como el Proyecto "Calha Norte", considerando que su desempeño mantenía "un alto 
componente de elección, elegido en cada caso en función de un cierto diagnóstico de la situación y de una constelación particular de alianzas".

El gran proyecto opera también como enclave político además de económico y por eso es antitético a cualquier planificación regional, fue la deducción certera de Vainer y Araújo (1992, p. 49-50). Al fin y al cabo, queda siempre la "región ex post", el propio hábitat hecho para y por la gran empresa. Una región que se vuelve coherente con la exogenia de los actores involucrados y con su carácter autorreferente. La región anfitriona, anteriormente receptora de políticas públicas, se convierte en un espacio que invita a dinámicas inescapables de apropiación de sus recursos por medio de macropolíticas sectoriales que reconfiguran verticalmente el espacio nacional.

En el caso, del sector eléctrico, antes bajo el control estatal, se transformó en un vector para la estructuración del territorio debido a su capacidad técnico-económica y político-institucional. Después de su privatización, después de años 1990, surgieron institucionalidades paralelas y formas particulares de ejercicio del poder empresarial. Si en los años 70 y 80 un gran proyecto hidroeléctrico materializaba "espacios socialmente segregados, jurisdicciones territoriales especiales" (op cit. 1992, p. 39), hoy los GPI llamados "estructurantes" o performativos suponen un nivel superior de articulación interescalar y una mayor pretensión homogeneizadora de la (re)regulación atractiva a los inversionistas. Además de eso, como fueron concebidos inicialmente en el marco de programas nacionales y sudamericanos (PAC e IIRSA-COSIPLAN) y después convertidos en portafolios de proyectos de alto retorno financiero en el PPI, son hoy parte integrante de un menú seleccionado de enclaves prioritarios por instalar. Quien continúa organizando y presentando dicho menú no es una forma estatal cualquiera sino un tipo particular de Estado reformateado, cuyas agencias de planificación ya fueron tercerizadas o incubadas por monopolios privados.

\section{Amazonia como reserva de megavatios}

La región amazónica pasó a desempeñar un papel rebajado de soporte y profundización de un modelo de especialización regresivo reconocido por el uso intensivo de recursos naturales, por la flexibilización de los derechos territoriales y de normativas ambientales y por la precarización y desvalorización de la fuerza laboral. El lugar del capital en la línea de las incorporaciones territoriales siempre es negociable: la apertura de fronteras para nuevos y más profundos negocios con 
bienes/derechos sociales y ambientales depende del grado de interpenetración entre los capitales y el Estado, y subsecuentemente del alcance de las bonificaciones mutuas.

No son solamente los capitales estrictamente referidos que proyectan ventajas de ubicación, sino que las propias ubicaciones (ciudades, departamentos, países) ofrecen ventajas a través de la flexibilización de la legislación y de las políticas sociales y ambientales. Las políticas macroeconómicas y de atracción de inversión además se sustentan por medio de acciones micropolíticas de consentimiento, es decir, el control corporativo se enraíza en la subjetividad y en el cotidiano de las personas y de los grupos sociales. Benson y Kirsch (2010) designan esa domesticación como "política de resignación" frente a agentes empresariales y gubernamentales y de sus proyecciones de hecho consumado de los procesos de expansión de las relaciones mercantiles y de los posteriores despojos. Subjetividad disciplinar que impone en la población una percepción de impotencia e incredulidad ante cualquier otra postura que no sea la de adecuación y adhesión pragmática a las dinámicas monopólicas vigentes.

Al analizar los principales proyectos minerales en la Amazonía, Sevá (2010) designaba que los receptáculos espaciales de los principales centros mineros y metalúrgicos instalados, o en instalación, como "territorios corporativos de escopo regional". La retrospectiva de la desterritorialización de la "Amazonia mineral", ya mapeada y detallada por muchos investigadores, indica como el mismo método de incorporación y despojo se repone en la "Amazonia hidroeléctrica", en un proceso de retroalimentación.

El territorio corporativo establece sus propios espacios de jurisdicción que el Estado luego legitima, ya sea debido a la falta de licencias y planificación pública, o mediante la aprobación de acuerdos extrajudiciales específicos en forma de Términos de Ajuste de Conducta (TACs). Por lo tanto, el camino es claro para la desfiguración de las múltiples territorialidades, haciendo que las medidas de indemnización, la mitigación de los impactos y otras medidas compensatorias sean percibidas como obsequios o dadivas. De un lado, se presenta la territorialidad que es la que se enuncia desde la memoria como resultado de interacciones materiales y simbólicas continuadas entre una colectividad dada y su entorno inmediato. De otro, con todas las prerrogativas jurídicas y financieras garantizadas de antemano, los grupos 
empresariales comienzan su territorialización unidireccional como "la territorialización del monopolio y la monopolización del territorio" (OLIVEIRA, 2004, p. 43).

Ejemplar, en este sentido, fue la descomposición de la legislación ambiental para aprobar tanto la licencia de las hidroeléctricas en el río Madeira (UHE Santo Antônio y Jirau) como en el río Xingu (UHE Belo Monte). Proceso considerado prototípico "de una tendencia en Brasil para la flexibilización de los requisitos ambientales y la flexibilización del proceso de licenciamiento" (FEARNSIDE, 2014, p. 1); en el marco de una "trayectoria de autolicenciamiento de los emprendimientos privados con una diligente validación gubernamental que los inmuniza contra eventuales acciones judiciales" (NOVOA GARZON, 2008, p. 45).

El caso de las hidroeléctricas en el río Madera y en el rio Xingu demuestran como la generación eléctrica de un país puede ser estrictamente encajada en el marco de los dictámenes de las inversiones privadas. Ejemplos elocuentes de esa instrumentalidad fueron: Inventarios y estudios ambientales por encomienda, licencias permisibles y moldeables, autorizaciones de operación anticipada, incluyendo un límite mínimo/máximo de derechos y compensaciones en las áreas de afectación. La dam industry (SEVÁ, 2012; BERMANN \& HERNANDES, 2010) es reconocidamente experta en transformar bienes de uso potencialmente común en inflexiones monopolistas de incorporación territorial.

Los territorios de excepción, tal como en la "ciudad de excepción" categorizada por Carlos Vainer (VAINER, 2011), implican un régimen de renuncia o de readecuación permanente a la última línea de fuerza establecida por sus controladores privados mayoritarios. Los megaproyectos desgastan las ya erosionadas regulaciones públicas, como las normas de política ambiental o las normas urbanísticas previstas constitucionalmente. Lo ambiental y lo urbano como porciones intercambiables de los territorios corporativos significan la cesión de los territorios vividos como mera plataforma física, como "territorios de excepción" (NASCIMENTO, CASTRO, 2017) para los grandes negocios en el presente y en el futuro.

Frente a tales prácticas corporativas impermeables al control social es necesario evaluar como son manejados y manipulados los indicadores de "sostenibilidad" o de "responsabilidad social corporativa". Las innovaciones ambientales y asistenciales constituidas en ese marco no pueden ser presentadas 
como un "avance progresivo y previsible" de la ciencia y la tecnología. Son soluciones solamente en el ámbito discursivo de modo a internalizar simbólicamente cautelas ambientales para lavar preventivamente la imagen (greenwashing y social washing) de emprendimientos asociados a impactos socioambientales irreversibles. (WATSON, 2017)

Conceptos en su origen críticos y desnudadores son constantemente usurpados por aquellos que necesitan actualizar y densificar sus máscaras. El proceso de ambientalización², al expropiar el sentido de las pérdidas, acelera las expropiaciones de las territorialidades y modos de vida. Los constantes agendamientos propuestos por asociaciones empresariales y grandes ONGs acerca de riesgos que acometen el planeta, como se hubiera un medio ambiente de todos y con "efectos comunes a todos", demuestra la conversión de la cuestión ambiental en un campo de legitimación estratégico para reciclar el discurso dominante y al mismo tiempo vaciar la crítica social. Es una anticipación que busca mapear posibles obstáculos en la implementación de los megaproyectos y proporcionar los canales apropiados para el "manejo de conflictos". Por eso, a pesar de los avances institucionales anunciados, predomina una agenda de cooptación de liderazgos locales y de encapsulamiento de los conflictos.

Ejemplo sintomático de eso fueron las compensaciones de los megaproyectos implementados en la Amazonia en la última década, particularmente las centrales hidroeléctricas de Santo Antonio, Jirau y Belo Monte. Esas compensaciones a principio destinadas para los municipios, distritos y segmentos más a afectados sufrieron alteraciones en el transcurso y no fueron implementadas en los sectores elegibles para reparaciones prioritarias. (MORAN, 2020; ARAUJO, NOVOA GARZON, 2020)

Otros dispositivos que componen ese régimen territorial de excepción son la desinformación programada para evitar contestaciones, la imposición de negociaciones individualizadas para reducir los montos de indemnización, la cooptación en serie de líderes y la criminalización de las organizaciones que osen mantenerse autónomas. El blindaje judicial y político de los megaproyectos en Brasil,

\footnotetext{
2 Se puede definir "ambientalización” como un proceso de internalización por grupos econômicos de temáticas ambientales convirtiéndolas em formas, lenguajes y performances que institucionalizan y silencian los conflictos ambientales de hecho (LEITE LOPES, 2006).
} 
si, por un lado, produjo un apaciguamiento de algunos movimientos sociales que tenían que contentarse con estrechos márgenes para negociar revisiones y reparaciones, por otro, generó un duro aprendizaje, en el interior de esos mismos movimientos, sobre la imposibilidad de obtener transformaciones efectivas solamente por medio de canales institucionales.

Las negociaciones con la población directamente afectada por las obras o por los lagos de las hidroeléctricas ilustran un escenario de cristalización políticoadministrativa de los designios empresariales. Las contrapartidas ofrecidas a los afectados fueron de tres órdenes: indemnización monetaria, carta de crédito para adquisición de vivienda y reasentamiento rural o ribereño. Sin embargo, los reasentamientos ni de lejos recompusieron las condiciones de reproducción material y simbólica que tenían las familias campesinas y ribereñas. Las cartas de crédito y las medidas indemnizatorias, tal como fueron administradas no garantizaron el reemplazo residencial y profesional de los desplazados.

Como se vio, cuanto más dependientes de las inversiones extranjeras y multinacionales sean los países, más tolerarán o coparticiparán en las violaciones socioambientales generadas por esas corporaciones. A medida que avanzan las interlocuciones entre inversionistas y agencias públicas, las reglas de protección social y ambiental son obnubiladas por otorgaciones y concesiones hechas bajo medida para las grandes empresas. Para Almeida (2010), las estrategias activadas por los intereses vinculados al neoextractivismo tienen como fin expandir su dominio sobre amplias áreas de tierra y territorio. Estas estrategias se rehacen y se actualizan en el ámbito de los distintos poderes (Legislativo, Judicial y Ejecutivo) en las tres esferas (Federal, Estatal y Municipal), con el objetivo de debilitar las disposiciones constitucionales que garantizan los derechos territoriales de las comunidades campesinas y tradicionales.

\section{La experiencia de licenciamiento de hidroeléctricas en la Amazonia: espetacularización de sostenibilidad y ocultamiento de daños}

Inefectivo y sin el acoplamiento de instrumentos de planificación regional y territorial, el licenciamiento ambiental en Brasil no puede ser caracterizado propiamente como un obstáculo que se interponga al proceso de especialización económica regresiva del país. Aun así, preocupados por la rentabilidad futura de los 
negocios basados en los recursos naturales, los grandes conglomerados son reacios a aceptar, incluso hipotéticamente, evaluaciones sistemáticas de los efectos sociales y ambientales de sus empresas a partir de criterios previamente establecidos. No es difícil entender que las inversiones concebidas y empaquetadas para producir solamente ganancias extraordinarias para los controladores y asociados busquen inmunizarse contra cualquier posibilidad de escrutinio técnico o social.

No hay forma de separar el vigor de los negocios intensivos en recursos naturales en Brasil, en las últimas dos décadas, de la debilitación y retracción de las normativas ambientales vigentes en el país. La Política Nacional del Medio Ambiente (Ley 6938/1981), que era aceptada pacíficamente como premisa de legitimidad y soberanía nacional entre las décadas de 1980 y 1990, pasó a ser representada en el discurso corporativo y gubernamental como traba y costo adicional, a partir del boom de commodities de los años 2000. El modelo de especialización productiva brasileño, basado en la provisión de suministros a partir del uso intensivo de los recursos naturales, pasa a definir el rol cosmético y abastardado de su política ambiental.

El licenciamiento ambiental, por lo tanto, es apenas la punta del hilo que, si se recoge, nos lleva al modelo hegemónico de una nueva, y supuestamente ventajosa, primarización de la economía del país. El desmantelamiento de las normativas ambientales expone un contencioso entre una dinámica de territorialización empresarial por un lado y una territorialización social y comunitaria por otro. Lo que está en juego es el arbitrio de las empresas para afectar nuestras vidas versus nuestra capacidad de limitar y condicionar ese poder que tiende a la absolutización. Un licenciamiento ambiental encogido, o en modo fast track, servirá para estabilizar y legitimar relaciones sociales y espaciales ya profundamente asimétricas. Tanto así que lo que ha prevalecido en el diseño institucional de las instituciones financieras multilaterales y de los gobiernos últimamente adiestrados es el cruce de las agencias que regulan y/o estimulan sectores productivos y de infraestructura con las agencias reguladoras de medio ambiente. El proceso de licenciamiento ambiental se convierte así en un mero sustituto del metabolismo empresarial o se subordina a él, teniendo como función no más que regular los efectos indeseables de la descoordinación de capitales individuales que actúan sin el paralelismo previsto en la lógica monopolista (ACSELRAD, 2007). 
Aun así, se hizo común, ya sea en el campo empresarial, o en el campo gubernamental relacionado, maldecir las dificultades producidas por las licencias ambientales. El "medio ambiente", los ambientalistas, los "ribereños", quilombolas (afrodescendientes) y etnias originarias son presentados, por lo tanto, como óbices para el crecimiento, la expansión de los cultivos agrícolas y la generación hidroeléctrica, agentes corresponsables de cualquier "apagón" o desabastecimiento que pueda ocurrir. Cuestión de "seguridad económica", alegan los juzgados de segunda instancia alegando ser inaceptable cualquier evaluación de mérito sobre proyectos que, si se paralizan, traerían "grave riesgo para la economía pública"3.

Tratándose de suministro de energía eléctrica en Brasil se combinan el chantaje implícito vinculado al riesgo magnificado de un apagón eléctrico y el chantaje explícito de expandir prontamente la generación de energía termonuclear para que no se frene la expansión de la frontera hidroeléctrica sea en territorio brasileño sea en el continente sudamericano. La pregunta que debe siempre ser repuesta es: ¿quién necesita consumir energía en tan grandes bloques y en tan corto plazo? Definitivamente no son los comunitarios, los campesinos, los trabajadores y los micro y pequeños empresarios que, cuando tienen acceso a los servicios de energía, se ven obligados a soportar una perversa tarifa invertida, que materializa los elevados lucros de las distribuidoras privadas.

Quién arroga el privilegio de disponibilidad inmediata de energía subsidiada son los mismos sectores electro-intensivos, exportadores de productos básicos, asociados a las propias concesionarias-constructoras de los megaproyectos. En verdad, sin discutir previamente cual es el perfil predominante de la demanda de energía en el país, vinculado a un determinado modelo energético y económico, estaremos siempre a punto de hacer sacrificios adicionales en términos ambientales, sociales y de soberanía en nombre de una expansión energética desasociada de cualquier horizonte de sociedad o de país.

\footnotetext{
3 "No se puede dejar de considerar el grave riesgo para la economía pública, en caso de que no se implemente el cronograma trazado en virtud de alguna eventual medida de anticipación o de salvaguardia de derechos" es lo que consta en los motivos del Presidente del Tribunal Regional Federal de la Primera Región, Jirair Aram Meguerian, para anular la medida que suspendía la licencia ambiental de la UHE de Jirau el 04/12/2008.Disponible en: https://www.conjur.com.br/2008-dez-05/trf_regiao_suspende_liminar_libera_obra_jirau
} 
5. Trayectoria reciente de Electrobras y tratativas de integración eléctrica regional

Que la electricidad se convierta en un activo financiero en Brasil, no hay novedad desde las reformas privatistas de la década de los años 1990, pero que el conjunto de la infraestructura y los territorios relacionados sean concebidos y gestionados como dinamizadores de los flujos financieros, es un retroceso civilizatorio, una prueba inequívoca de automutilación política y de supresión de pactos sociales y políticos. La construcción de ambientes para la reproducción del capital deja de ser un circuito secundario de acumulación (LEFEBVRE, 2008); o sea, esos ambientes dejan de ser espacios accesorios para la acumulación y se convierten en fuentes primordiales de acumulación. No es casual que Electrobras, aunque sea una estatal, tenga demostrado, en los últimos 15 años, una trayectoria de desinversiones y de privatización de sus subsidiarias, es decir, de automutilación de su papel articulador del sector energético y consecuentemente del ritmo y dirección de la economía.

Objetivamente, hubo una acumulación de influencia privada en la estatal a lo largo de ese período, un poder inercial y permanente del oligopolio privado que fragmentó y se apoderó del sector eléctrico en la década de 1990, transformando cada una de sus fases (generación, trasmisión y distribución) en un negocio. Fragmentadas la generación, la transmisión y la distribución en nichos puramente comerciales, se inauguró un mercado que ofreció alta rentabilidad a los operadores privados y transnacionales. Se les abrió además la posibilidad de planificar la misma expansión y condicionar el uso final de la electricidad en el país, detentor formal de las fuentes de energía.

El marco regulatorio del sector eléctrico buscó favorecer la "interacción estable" entre los agentes privados. La meta es la autonomización del acuerdo oligopolista frente a legítimas demandas de la población o de la nación. Los cambios introducidos en 2004 (Ley 10.848) por la entonces ministra de Minas y Energía, Dilma Rousseff, no cambiaron el escenario de descapitalización de Electrobras; más bien se multiplicaron las funciones de intermediación comercial en el sistema eléctrico, se ampliaron las tarifas pagadas por la población y se consolidó un mercado de energía libre para grandes consumidores, lo que distorsionó el perfil de la demanda nacional (ESPÓSITO, 2012). 
El desmembramiento de Electrobras y la captura de sus filiales regionales por grandes conglomerados con estrategias regionales específicas ayuda también a explicar el pequeño radio de maniobra que el gobierno tiene para intervenir en el sector, un escopo de actuación voluntariamente delimitado, subráyese. Se trata de una decisión política de no contrariar los principales intereses corporativos y, al mismo tiempo, tener en ellos aliados permanentes.

Por este motivo, la investigación sobre las estrategias de los conglomerados privados y sus interfaces con las agencias públicas propicia la revelación de la dinámica interescalar de las incorporaciones territoriales en Brasil desencadenadas por el sector eléctrico y así vislumbrar como se entrecruzan las geometrías de poder, jerarquías tanto amplias cuanto cercanas.

Los anuncios y propuestas de la privatización integral de Electrobras por el gobierno de Temer (2016-2018) y en seguida, por el gobierno de Bolsonaro (2019 -...) representan una culminación, un punto de llegada coherente con las medidas debilitantes adoptadas por gobiernos anteriores. En este contexto de liquidación de la empresa estatal, los planes nacionales de expansión energética presentados por el Ministerio de Minas y Energía y la Compañía de Investigación Energética son, más que nunca, planes para la rentabilidad futura del sector, que evidencian por lo tanto reposicionamientos tendenciales en el mercado eléctrico nacional y regional. La Empresa de Pesquisas Energéticas, agencia estatal responsable por esa planificación sectorial, asume sin ningún pudor que sus proyectos "más viables" de futuras hidroeléctricas componen desde ya un "portafolio elegible" para inversiones privadas. (EPE, 2018)

En el último Plan Decenal de Expansión de Energía 2029, aprobado en 2019, consta que la ampliación de las interconexiones hoy existentes (Figura 1) entre BrasilParaguay, Brasil-Argentina-Uruguay y Brasil-Venezuela ${ }^{4}$ y la creación de nuevos puntos de interconexión, están siendo objeto de estudio y de negociaciones específicas "en el ámbito de acuerdos internacionales entre el gobierno brasileño y los países fronterizos sudamericanos rumbo a la integración energética regional" (PDE 2029 ,

\footnotetext{
${ }^{4}$ A partir de marzo de 2019, esta interconexión se encuentra fuera de servicio.
} 
Figura 1: Proyección de la transmisión, entre 2018 y 2027.

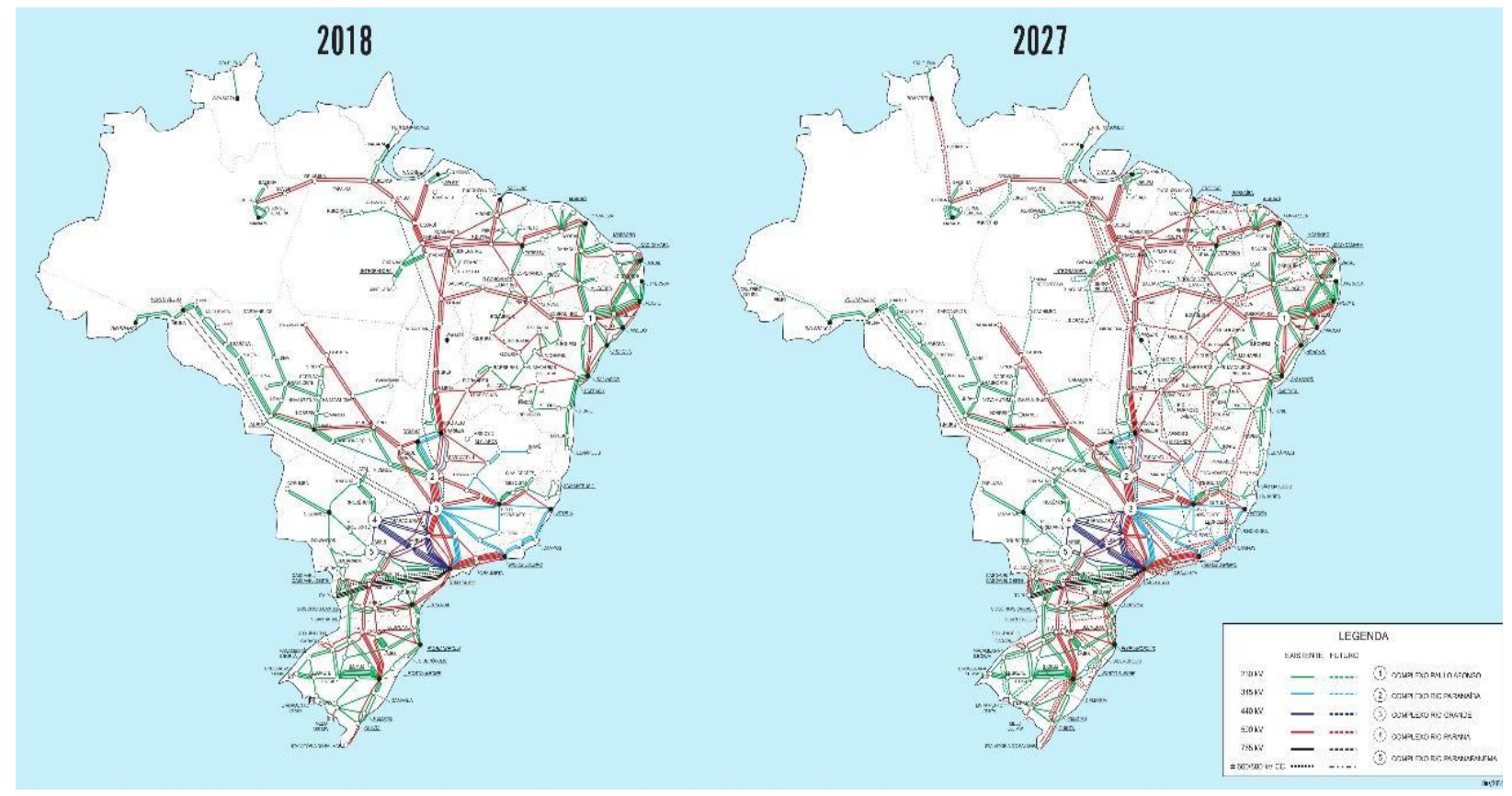

Fuente: Electrobras (2018) con incorporaciones del autor.

Lo que se busca específicamente es el señoreaje sobre "enorme potencial hidroeléctrico binacional" retenido en las cuencas del Plata y del Madera. Predomina en esa búsqueda la lógica ofertista (oferta adicional subsidiada) de excedentes energéticos para atraer inversiones externas en plantas electro-intensivas de minería y celulosa. Se trata de amplificar en escala sudamericana un subsidio eléctrico injustificable para sectores reprimarizadores de nuestras economías, que generan empleos precarizados y efectos socioambientales irreversibles en nuestros territorios.

Para que no queden dudas del nivel de (des) compromiso de los gestores del sector eléctrico con la sociedad y el medio ambiente, el documento prospectivo de la EPE prescribe "inventarios hidroeléctricos participativos", pero no con los potenciales afectados, sino como los posibles bloqueadores de los procesos de decisión de inversiones, como los órganos de control ambiental o el Ministerio Público, a modo de "anticipar cuestiones críticas, aumentando la seguridad y previsibilidad de la regularización de los emprendimientos" (PDE 2029, p. 253).

La misma meta de convertir la planificación energética regional en una planificación meramente corporativo-financiera se destaca en el Plan Nacional de Energía 2050. Siguiendo el argumento binario del liberalismo, los países con vocación de exportar energía deben especializarse y profundizar en la tarea, mientras los 
países importadores deben garantizar el fiel suministro con los mejores costos operativos y finales. Si en un primer momento, Paraguay, Venezuela y Bolivia se destacaban como exportadores y el Brasil apuntalaba como importador, en un segundo momento - dependiendo del alcance de las ofensivas de incorporación de biomas y comunidades del continente - será la América Latina en bloque que exportará energía. Un continente especializado en encomiendas de enormes bloques de energía al gran mercado del norte y a los grandes consumidores electro-intensivos, donde sea que se encuentren en el hemisferio americano. Desde esta óptica estricta y miope, la integración energética regional impide el "desvío de comercio" y "crea comercio", crea una zona más tangible de "libre comercio".

Las proyecciones hechas por consultorías y grupos empresariales que actúan históricamente en el marco de la Comisión Integración Eléctrica Regional (CIER) nunca dejaron de considerar este escenario (Figura 2), pero la diferencia es que las ansiadas "convergencias regulatorias" del regionalismo abierto se han convertido, en los últimos años, en marcos regulatorios únicos. Así se reúnen piezas centrales que prefiguran el rompecabezas de energía del "mercado eléctrico latinoamericano".

Figura 2: Proyección del mercado eléctrico latinoamericano como mercado hemisférico

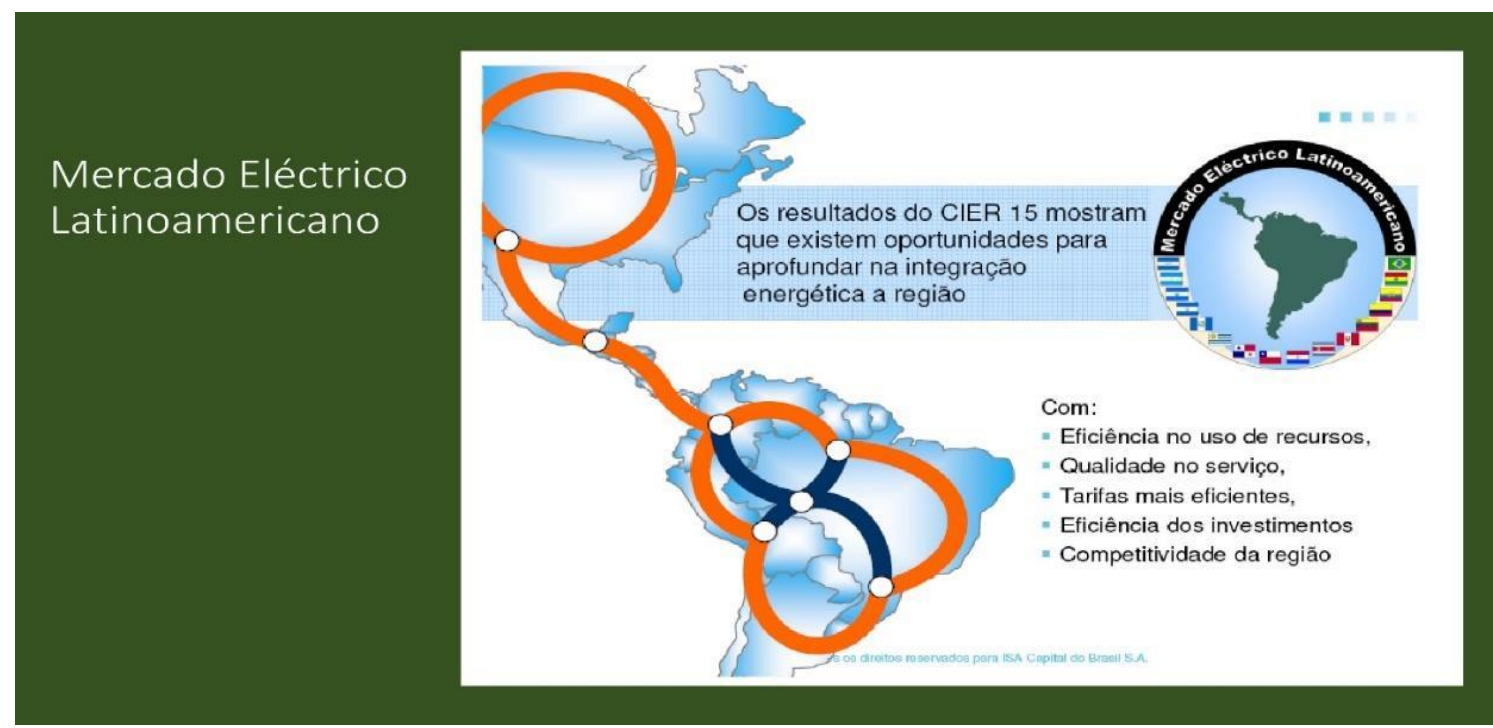

Fuente: ISA Capital del Brasil S. A (2010).

En un pronunciamiento reciente ${ }^{5}$, el actual presidente de Electrobras, muy convenientemente también el presidente de la rama brasileña de CIER, la BRACIER,

\footnotetext{
${ }^{5}$ Agência Estado, 23/07/2019
} 
anticipó de forma sustantiva cuan prioritaria es para Brasil la integración energética regional: 15 mil millones de dólares estarían ya asignados a proyectos conjuntos de generación y transmisión con Argentina, Bolivia y el llamado Arco Norte (BrasilSurinam-Guyana) como una ruta alternativa al paso venezolano. El anuncio generó expectativas infladas y disputas previas por el monto anunciado junto a los inversores de la Bolsa de Valores de São Paulo (B3 - Brasil, Bolsa, Balcón). Fue necesario que una dirigente de la ELETROBRAS reiterase las previsiones de aportes, de manera oficial (Figura 3). El comunicado no deja duda sobre quien maneja y dicta el ritmo de la empresa estatal, aparentemente financiarizada antes de ser privatizada.

Figura 3: Comunicado de Electrobras al mercado de accionistas. 


\section{COMUNICADO AO MERCADO}

CENTRAIS ELÉTRICAS BRASILEIRAS S/A

CNPJ: 00.001.180/0001-26 | NIRE: 533.0000085-9

COMPANHIA ABERTA

Centrais Elétricas Brasileiras S/A Centrais Elétricas Brasileiras S/A ("Companhia" ou "Eletrobras") (B3: ELET3, ELET5 \& ELET6; NYSE: EBR \& EBR.B; LATIBEX: XELT.O \& XELT.B), informa aos seus acionistas e ao mercado em geral que recebeu, no dia 23 de julho de 2019, da B3 - Brasil, Bolsa, Balcão, o Ofício 598/2019-SLS, solicitando esclarecimentos a respeito de notícia veiculada pela Agência Estado - Broadcast, em que constam as informações transcritas a seguir:

Transcrição do Ofício 598/2019-SLS:

"Centrais Elétricas Brasileiras S.A. - Eletrobras

At. Sra. Elvira Baracuhy Cavalcanti Presta

Diretora de Relações com Investidores

Ref.: Solicitação de esclarecimentos sobre noticia veiculada na imprensa

Prezados Senhores,

Em notícia veiculada pela Agência Estado - Broadcast, em 23/07/2019, sob o título "Eletrobras estuda mais de US\$ 15 bilhões em projetos internacionais" constam, entre outras informações, que:

1. O presidente da Eletrobras, Wilson Ferreira Junior, defendeu nesta terça-feira projetos de integração energética na América do Sul;

2. O executivo, que por sua posição na estatal também é presidente do Bracier, comitê brasileiro da Comissão de Integração Elétrica Regional (CIER), reforçou que a estatal estuda diferentes projetos de geração e transmissão de energia internacionais, com paises como Bolívia, Argentina e também na fronteira ao Norte, com investimentos que somam mais de US\$15 bilhões.

Solicitamos esclarecimentos sobre os itens assinalados, até 24/07/2019, com a sua confirmação ou não, bem como outras informações consideradas importantes."

Em atenção ao Ofício acima mencionado, esclarecemos que:

1. O valor divulgado, de cerca de US\$ 15 bilhões, refere-se ao montante global estimado dos projetos em análise pela Eletrobras no exterior, contemplando tanto a participação da Companhia quanto eventuais investimentos de sócios e parceiros internacionais. Assim, o montante informado não representa o total de investimentos diretos da Eletrobras no exterior.

2. Todos os projetos citados na notícia estão em fase inicial de estudos, e quando concluídos serão ainda submetidos à aprovação dos órgãos deliberativos da Companhia para apreciação, quando serão oportunamente divulgados.

Rio de Janeiro, 24 de julho de 2019.

Elvira Cavalcanti Presta

Diretora Financeira e de Relações com Investidores

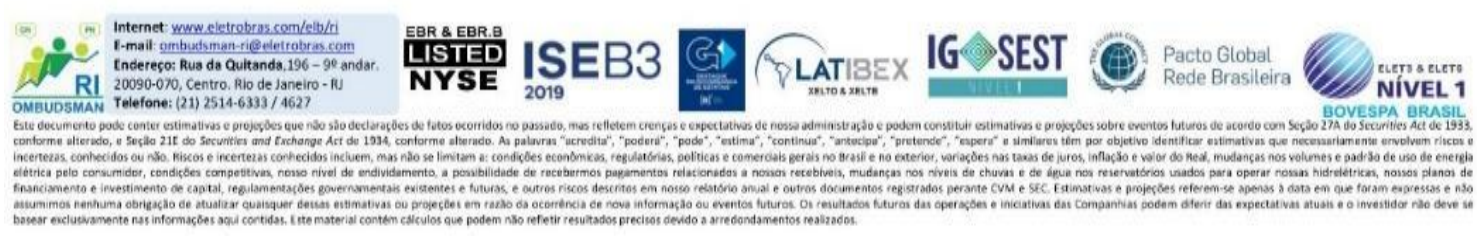

Fuente: Electrobras (2019)

En el caso boliviano, el BID (Banco Interamericano de Desarrollo) y la CAF (Corporación Andina de Fomento) propiciaron estudios y recursos adicionales para el 
aprovechamiento integral de la Cuenca del rio Madera, lo que incluiría de inmediato una Hidroeléctrica binacional (Ribeirao) e otra boliviana (Cachuela Esperanza) ${ }^{6}$. Poner en escena como si fuera ejemplar el modelo energético-exportador con basis en la consigna "Bolivia, corazón energético de América del Sur", sin que se cuestione a quien serviría tal pulsación, denota una infame celebración del neoextractivismo exportador. Ampliar el abastecimiento energético de los cinturones de minería y del agronegocio, dirigido por y para cadenas financieras y productivas foráneas, no representa otra cosa sino la adhesión a un regionalismo de encomienda promovido por un continente con un destino predefinido, una sumatoria de países condenados a provisionar cadenas globales de valor. ¿Que soberanía puede haber si no se puede priorizar los mercados internos de ese llamado "mercado regional"?

Proporcionalmente a los esfuerzos del BID y de la CAF para viabilizar el mercado eléctrico regional en el marco hemisférico, instituciones chinas de financiamiento y fomento, junto con multinacionales estatales como State Grid, han participado de adquisiciones de diversos trazados de conexión eléctrica en el Brasil y en el continente sudamericano. La influencia china en el sector también se hace visible en la actuación de la Organización Mundial de Cooperación y Desarrollo de la Interconexión Energética (GEIDCO), que busca dar coherencia y sentido transpacífico a las inversiones chinas en la región.

\section{Consideraciones finales}

En Brasil la cuenta de este reordenamiento de fuerzas, realzado con la elección de Jair Bolsonaro en 2018, se va pagando con contrarreformas en la seguridad social, en la educación y en la salud, con la continua flexibilización de los derechos laborales y territoriales, con la destrucción y privatización de los bienes públicos y con la brutal mercantilización y supresión de territorios, biomas y comunidades. (NOVOA GARZON, 2019)

A partir del análisis retrospectivo de los procesos de implementación de las principales obras de infraestructura enlistados en IIRSA, como es el caso de las

\footnotetext{
${ }^{6}$ Los estudios de inventario de las posibilidades de aprovechamiento de energía de los ríos Madera, Abuná, Beni, Mamoré y sus afluentes, para generación de electricidad, fueron contractados por las estatales ENDE (Bolivia) e ELETROBRÁS (Brasil) pero aun no fueron finalizados ni publicados de forma integral. Informaciones preliminares de eses estudios están disponibles en sitio electrónico creado por las dos empresas publicas. Link: https://www.inventariobinacional.com/es/index.php
} 
centrales hidroeléctricas de Jirau y San Antonio en el río Madera, buscamos prospectar las chances de aplicación de regulaciones sociales y ambientales en los nuevos grandes proyectos que se avecinan. Podemos afirmar que esos megaproyectos que cargan la "marca IIRSA", entre otros que la disimulan, dependen de ciudadelas de poder irrestricto, dependen de "no lugares" políticos para ser implementados; en otros términos, dependen de zonas autónomas y libres de cualquier normatividad social.

De forma liminar, se puede afirmar que la entronización del modelo de incorporación territorial a gran escala en Brasil e Sudamérica en las últimas decadas dependió de las siguientes premisas:

a) planificación alineada a las determinaciones exógenas-endógenas de circuitos de suministro global;

b) planificación sectorial privada realizada en marcos paraestatales ${ }^{7}$ automáticamente validados;

c) financiamiento de megaproyectos por medio de arquitecturas financieras ${ }^{8}$ con funding público que cristalizan amplios márgenes de rentabilidad en desmedro de cualquier costo socioambiental considerado "adicional;

En Brasil, siguiendo la matriz lógica que presidió tanto IIRSA como al PAC, en 2016 se lanzó el Programa de Asociaciones de Inversiones (PPI en la sigla en portugués). El títere de turno de los mercados en la Presidencia solo podría radicalizar la lógica de maximizar del apoyo público a los conglomerados privados y minimizar los mecanismos de regulación pública y social. El Gobierno Bolsonaro hereda el PPI y busca tornarlo exequible cubriendo y encubriendo riesgos e incertezas sociales y ambientales. Existe acuerdo en el bloque de poder siempre que se mantenga la posibilidad de readecuaciones continuadas en las concesiones y licencias de explotación de los territorios, sin que haya costos administrativos y riesgos financieros adicionales. Tales programas primero adecúan las reglas sectoriales a los acuerdos empresariales más articulados y luego después se disponen a darles variados bonos tales como exenciones, subsidios, indemnizaciones por eventuales pérdidas de rentabilidad, entre otros beneficios obscenamente anticoncurrenciales.

\footnotetext{
7 Aquí traduzco a mi manera el concepto de statehood (literalmente "estatalidad" o paraestalidad) que comprendería, por un lado, desarrollos y repercusiones de la acción estatal más allá del aparato del Estado, y por otro, incorporaciones e incrustaciones de dinámicas privadas en este mismo aparato (BRENNER, 2004).

${ }^{8}$ Project finances.
} 
A nivel regional, los pasos dados para establecer una "estrategia energética sudamericana", a partir del Consejo Energético Sudamericano (CES), reafirman el compromiso de los esfuerzos conjuntos de países y pueblos en nombre de los beneficios sectoriales y empresariales. ¿Qué se anhela con la "promoción de la industrialización y la complementación energética regional" (CES, 2016)? ¿Interconectar los cinturones de minería y agricultura del continente para optimizar el volumen de exportaciones de productos poco elaborados y productos básicos, con uso intensivo de energía? ¿Y qué decir de la meta de "estimular la asociación del sector público con el sector privado" que resalta la proximidad invariablemente perjudicial para el primero y ventajosa para al segundo, considerando la práctica actual de recortes lineales y de privatizaciones dirigidas solamente a generar superávits para proporcionar la manutención y el canje de deuda pública?

Los rumbos de la integración energética regional están siendo definidos en medio de una contienda sino-americana en lo que atañe, tanto al comercio, como a las inversiones. Abstraídos de las necesidades y anhelos de los pueblos, los planes nacionales de los países sudamericanos enfatizan, como una especie de confesión de su impotencia, que la justificación de la integración energética es el desarrollo de Sudamérica en sus "múltiples dimensiones". El desafío de fondo es revelar proyectos económicos y geopolíticos de clase que se ocultan bajo el lema de integración energética, en sus distintas versiones. La tarea es exponer el modelo de planeación territorial que sigue en vigor, con o sin "ciclos políticos progresistas", explicitar las opciones hechas y las que están por ser hechas, en nombre de nuestras naciones.

Como inferencia final, subrayamos que políticas integracionistas no deben ser reducidas a una busca de usufructo común de eventuales externalidades positivas de las inversiones extranjeras. La Sudamérica, totalmente regida por dinámicas centrifugas, se convertiría en una zona económica indistinta, pendular, objeto de cálculo y desecho.

\section{REFERENCIAS BIBLIOGRÁFICAS}

ACSELRAD, Henri. Vigiar e unir: a agenda da sustentabilidade urbana? Revista VeraCidade, Ano 2, № 2, p. 1-11, 2007.

ALMEIDA, Alfredo Wagner. Agroestratégias e desterritorialização: direitos territoriais e étnicos na mira dos estrategistas dos agronegócios. In: ALMEIDA, Alfredo Wagner 
B. et al. Capitalismo globalizado e recursos territoriais: fronteiras da acumulação no Brasil contemporâneo. Rio de Janeiro. Lamparina, 2010, p. 101-144.

ARAUJO, Neiva; NOVOA GARZON, Luis Fernando. Neoextrativismo e projetos hidrelétricos em Rondônia: desdobramentos territoriais e seu significado políticoinstitucional. Revista Antropolítica, n. 49, Niterói, p. 72-100, 2020. Disponible en: https://periodicos.uff.br/antropolitica/article/view/42136/Neoextrativismo\%20e\%20proj etos\%20hidrel\%C3\%A9tricos\%20em\%20Rond\%C3\%B4nia\%20desdobramentos\%2 0territoriais\%20e\%20seu\%20significado\%20pol\%C3\%ADtico-institucional Acceso en 23/09/2020.

BENSON, Peter; KIRSCH, Stuart. Capitalism and the Politics of Resignation. Current Anthropology. Volume 51, Number 4, August, p. 459-486, 2010.

BERMAN, Célio., HERNANDES, Francisco. A usina de Belo Monte: energia e democracia em questão. Revista Política Democrática, n. 27, p. 43 - 57, 2010.

BRENNER, Neil. New state spaces: urban governance and the rescaling of statehood. Oxford: Oxford University Press, 2004.

CANO, Wilson. Brasil - construção e desconstrução do desenvolvimento. Economia e Sociedade, Campinas, v. 26, n. 2 (60), p. 265-302, ago. 2017.

CES - Consejo Energético Sudamericano. Boletín Informativo n.1, 2016.

DOS SANTOS, Fabio Luis Barbosa. Uma história da onda progressista sul-americana (1998-2016). 2ª ed. São Paulo: Elefante, 2019.

. Neodesenvolvimentismo ou neoliberalismo: integração regional sulamericana e ideologia. Revista da Sociedade de Economia Política, n. 45, outubrodezembro 2016, p. $1-27 . \quad$ Disponíble http://www.revistasep.org.br/index.php/SEP/article/view/272 Acceso en 08/11/2019.

DREIFUSS, René. 1964: A conquista do Estado. Rio de Janeiro: Vozes, 1981.

EMPRESA DE PESQUISAS ENERGÉTICAS (EPE). Considerações sobre a Expansão Hidrelétrica nos Estudos de Planejamento Energético de Longo Prazo. Documento de Apoio ao PNE 2050. Brasília: EPE, 2018.

. Plano Decenal de Expansão de Energia 2029. MME, Brasília, 2019.

ESPÓSITO, Alexandre Siciliano . O setor elétrico brasileiro e o BNDES: reflexões sobre o financiamento aos investimentos e perspectivas. In: DE SOUZA, Filipe Lage (Org.). BNDES 60 ANOS. Perspectivas Setoriais. Rio de Janeiro, 2012, p. 190-231.

FEARNSIDE, Philip. Barragens do rio Madeira - Sedimentos 2: O primeiro cenário oficial. Amazônia Real, 05 de maio de 2014. Disponible en: https://amazoniareal.com.br/barragens-do-rio-madeira-sedimentos-2-o-primeirocenario-oficial/ Acesso em 08/11/2019. 
FUSER, Igor; ABRÃO, Ricardo Almeida Ferreira. Integração energética na América do Sul: perspectivas, impasses e obstáculos. Brazilian Journal of Latin American Studies - Cadernos Prolam/USP, v. 19, n. 37, p. 240-267, out. 2020.

GARCIA, Ana Saggioro. Investimentos da China no Brasil, na África do Sul e na Índia: Arranjos Institucionais, Atores e Impactos. Revista Tempo do Mundo, (22), p.149-174, 2020. Disponible https://www.ipea.gov.br/revistas/index.php/rtm/article/view/240/208 Acceso em 20/08/2020.

LEFEBVRE, Henri. Espaço e política. Belo Horizonte: Editora da UFMG, 2008.

LEITE LOPES, José Sérgio. Sobre processos de "ambientalização" dos conflitos e sobre dilemas da participação. Horizontes Antropológicos, n. 25, p. 31 - 64, 2006.

MARTÍNEZ, Paola. Bolívia frente a la IIRSA-COSIPLAN: entre el extractivismo y la integración? Buenos Aires: CLACSO, 2013. Disponible en: http://biblioteca.clacso.edu.ar/clacso/becas/20131016053606/Informe.pdf Acceso em 30/04/2019.

MORAN, Emilio Federico. Changing how we build hydropower infrastructure for the common good: lessons from the Brazilian Amazon. Civitas, vol.20, n.1, p.5-15, 2020. Disponible en: https://www.scielo.br/scielo.php?script=sci arttext\&pid=S151960892020000100005\&lng=en\&nrm=iso\&tIng=en Acceso en 23/09/2020.

MOREIRA, Vânia Maria Losada. Os Anos JK: industrialização e modelo oligárquico de desenvolvimento rural. In: FERREIRA, J \& DELGADO, L. (Eds.) O Brasil Republicano- o tempo da experiência democrática, Rio de Janeiro: Civilização Brasileira 2003, p. 155-194.

MINEIRO, Adhemar, MELLO, Fátima, JAKOBSEN, Kjeld. As Instituições Financeiras Internacionais com participação do Brasil: seu papel atual. Brasília: INESC, 2018. Disponible en: https://www.inesc.org.br/es/as-instituicoes-financeiras-internacionaiscom-participacao-do-brasil-seu-papel-atual Acceso en 20/03/2020.

NEVES, Bárbara. Há uma luz no fim do túnel? Uma análise da situação atual do regionalismo sul-americano. Observatório do Regionalismo, REPRI, Fevereiro de 2020. Disponible: http://observatorio.repri.org/2020/02/18/ha-uma-luz-no-fim-dotunel-uma-analise-da-situacao-atual-do-regionalismo-sul-americano/ Acceso en 01/08/2020.

NASCIMENTO, Sabrina Mesquita do; CASTRO, Edna Ramos. Estado de exceção como paradigma do desenvolvimento: uma análise sobre a hidrelétrica de Belo Monte. In: CASTRO, Edna Ramos (Org.). Territórios em transformação na Amazônia saberes, rupturas e resistências. Belém: NAEA, 2017, p. 139-176.

NOVOA GARZON, Luis Fernando. O licenciamento automático dos grandes projetos de infraestrutura no Brasil: o caso das Usinas no rio Madeira. Universidade e Sociedade, ano XVIII, № 42, DF, p. 37-58, 2008. 
. Um Panorama dos Últimos 25 anos no Brasil: das ressurgências neoliberais às contrarrevoluções preventivas. Revista de Estudos e Pesquisas Sobre as Américas, v. $13 \quad$ (2), 203-229, $2019 . \quad$ Disponible en: https://periodicos.unb.br/index.php/repam/article/view/23733/23520 Acceso em 29/06/2020.

OLIVEIRA, Ariovaldo Umbelino. O Campo no Século XXI. São Paulo: Editora Casa Amarela, São Paulo, 2004.

PACHECO, João. Projeto Calha Norte: militares, índios e fronteiras. Rio de Janeiro: Ed. Da UFRJ/ PETI/ Museu Nacional, 1990.

PIQUET, Rosélia. Indústria do Petróleo e dinâmica regional: reflexões teóricometodológicas. In: PIQUET, R., VALENTE SERRA, R. (Eds.) Petróleo e região no Brasil: o desafio da abundância. Rio de Janeiro: Ed. Garamond, 2007, p. 15 - 34.

RIBEIRO, Gustavo Lins. Transnational capitalism and hydropolitics in Argentina: the Yacyretá high dam. Gainesville: University Press of Florida, 1988.

SEVÁ, Arsênio Oswaldo. Problemas intrínsecos e graves da expansão mineral, metalúrgica, petrolífera, e hidrelétrica nas Amazônias. In: ZHOURI, A.; LASCHEFSKI, K. (orgs.) Desenvolvimento e conflitos ambientais. Belo Horizonte: Editora UFMG, 2010, p. 114-147.

Capitalismo hidrelétrico em Minas Gerais: o Rio Grande e seus afluentes silenciados. In: NOGUEIRA et al. Universidade, Tecnologia e Sociedade, Viçosa: UFVJM, 2012, p. 1-39.

SANTOS, Leandro Bruno. Políticas públicas e internacionalização de empresas brasileiras. Sociedade \& Natureza, v. 27, n. 1, p. 37-52, 2015. Disponible en: https://www.scielo.br/scielo.php?pid=S1982-45132015000100037\&script=sci arttext. Acceso em 30/09/2019.

SVAMPA, MARISTELLA. Las fronteras del neoextractivismo en América Latina. Conflictos socioambientales, giro ecoterritorial y nuevas dependências. Bielefeld: Ed Calas, 2019.

VAINER, C. B., ARAUJO, F. G. B. Grandes Projetos Hidrelétricos e Desenvolvimento Regional. Rio de Janeiro: CEDI, 1992.

VAINER, C. B. Cidade de exceção: reflexões a partir do Rio de Janeiro. Apresentação Mesa Redonda "Política Urbana/ Planejamento territorial". Anais XIV Encontro Nacional da ANPUR - Rio de Janeiro, 2011.

VILLEGAS, Pablo. El rol central de la IIRSA en el modelo de desarrollo vigente en Bolivia". Petropress, febrero de 2011. Disponible en:

http://petropress.wordpress.com/2011/02/17/el-rol-central-de-laiirsa-en-el-modelo-dedesarrollo-vigente-en-bolivia-por-pablo-villegas-n Acceso em 05/04/2019

VITELLI, Marina; PERES MILANI, Lívia. Regionalismo sudamericano en tiempos de redefiniciones: el Consejo de Defensa de la UNASUR y la crisis del regionalismo 
posliberal y poshegemónico. Revista Uruguaya de Ciência Política, Montevideo, v. 28, n. 2, p. 35-60, 2019. Disponible em:

http://www.scielo.edu.uy/scielo.php?script=sci arttext\&pid=S1688499X2019000200035\&lng=es\&nrm=iso Acceso em 14/03/2020.

WATSON, Bruce. The troubling evolution of corporate greenwashing. Chain Reaction, No. 129, p. 38-40, 2017. Disponible en:

https://search.informit.com.au/documentSummary; $\mathrm{dn}=766428450523476$;res=IELHS $\underline{\mathrm{S}}$ Acceso en 26/09/2020.

WERNER, Deborah. Neoliberalização da Infraestrutura: Mudanças Regulatórias e Configuração do Setor Elétrico Brasileiro (1990-2018). Semestre Econômico, v. 22, n. 50, p. 151-177, 2019. Disponíble en:

http://www.scielo.org.co/scielo.php?script=sci arttext\&pid=S01203462019000100151 Acceso em 16/05/2020. 